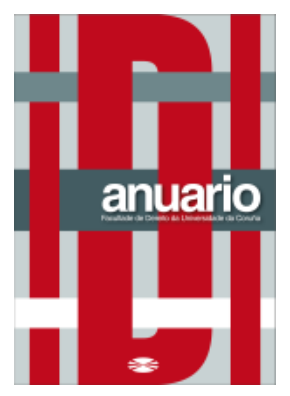

Anuario da Facultade de Dereito da Universidade da

Coruña Vol. 22 (2018), pp. 418-446

ISSNe: 2530-6324 || ISSN: 1138-039X

DOI: https://doi.org/10.17979/afdudc.2018.22.0.5193

\title{
AFORAMIENTOS E INMUNIDADES ESTUDIO COMPARATIVO DE LAS GARANTÍAS PARLAMENTARIAS EN MÉXICO Y ESPAÑA*
}

\author{
VÍCTOR ALEJANDRO WONG MERAZ \\ Doctor en Derecho por la Universidad Complutense de Madrid. \\ Docente en la Universidad Autónoma del Estado de México \\ CHRISTIAN YAIR ALDRETE ACUÑ \\ Máster en Ciencia Jurídico Penal por el Instituto Nacional de Ciencias Penales (INACIPE)
}

Resumen: El presente escrito tiene como objetivo realizar un estudio comparado entre México y España, respecto de las instituciones jurídico-políticas de las que gozan los representantes de la sociedad en el ejercicio del poder político, en estricto sentido de aquellas creadas constitucionalmente para el Poder Parlamentario y que se a saber son: la inviolabilidad, la inmunidad y el aforamiento. Instituciones de protección nacidas en aras del principio de división de poderes dentro de un Estado Constitucional Democrático de Derecho. Estudio que se realiza en busca de elementos que nutran y justifiquen el discurso de la necesidad de preservación de estas garantías constitucionales en la construcción constitucional en esta forma de Estado, dentro del cual se establezcan como elementos de control del poder, como contenidos materiales de la Constitución. Tema de relevancia en la

\footnotetext{
${ }^{*}$ El presente artículo académico es resultado de la estancia de investigación que se realizara en la Facultad de Derecho de la Universidad de A Coruña, España, como complemento a los estudios de Maestría que al momento se cursan en la Facultad de Derecho de la Universidad Autónoma del Estado de México, dentro del programa de Maestría en Estudios Jurídicos. Estancia efectuada bajo la supervisión de los Doctores Javier Ruipérez Alamillo, Catedrático de Derecho Constitucional del Departamento de Derecho Público de la Universidad de A Coruña; y, Doctor Víctor Alejandro Wong Meráz, Catedrático de la Universidad Autónoma del Estado de México.
} 
discusión sobre los límites del poder político en la democracia representativa. En él se hace una presentación histórica del nacimiento de estas instituciones jurídicas dentro del medievo inglés y el constitucionalismo liberal de la Francia revolucionaria, hasta llegar a la percepción actual del constitucionalismo ibérico y mexicano respectivamente. De igual forma se abordan las formas de concepción normativa y práctica de estas instituciones de protección estatal y en específico de la recaída en la aplicación del aforamiento parlamentario.

Palabras clave: Constitución, separación de poderes, inviolabilidad parlamentaria, inmunidad parlamentaria, aforamiento.

\begin{abstract}
The goal of this document is to do a comparative study between Spain and Mexico in respect to the judicial-political institutions enjoyed be the representatives of society in its exercise of political power and in the strict sense of those constitutionally created for Parlementary power, which in essense are: inviobility, immunity and appraisal. Protective institutions born for the sake of the principle of the division of powers within a Democratic Constitutional State of Law. This study will search or elements that will add to, and justify, the discourse for the need to preserve these constitutional rights in the construction of this form of government, within which are established the elements of control of power such as the material content of the constitution; relevant topic in the discussion on the limits of political power in a representative government. This study will include a historical presentation of the birth of these legal institutions in England during the middle ages and the liberal constitutionalism of revolutionary France, and up to the current perception of Iberian and Mexican constitutionalism. Likewise, the forms of normative and practical conceptions of these institutions of state protection will be revised, and specifically the relapse in the application of parlamentary appraisal.
\end{abstract}

Keywords: Constitution, separation of powers, parliamentary inviolability, parliamentary immunity, appraisal.

SUMARIO: I. INTRODUCCIÓN; II. DEL PARLAMENTO Y SUS INSTITUCIONES DE PROTECCIÓN; 1. El parlamento medieval inglés; 2. El parlamento herencia de la Revolución francesa; III. INVIOLABILIDA E INMUNIDAD; 1. Naturaleza, finalidad y efecto; 2. Efectos en el caso español; 3. Efectos en el caso mexicano; IV. AFORAMIENTO; 1. Aforamiento en España; 2. Aforamiento en México; V. CONCLUSIONES; VI. FUENTES DE CONSULTA.

\title{
I. INTRODUCCIÓN
}

En el seno del pluralismo democrático ventilado a la luz de la libertad de expresión en pro de un adecuado constructivismo del discurso social, político y jurídico, se han creado figuras necesarias para la operatividad del Estado, entendido éste como ese ente 
$\operatorname{organizador}^{1}$ de la vida social de la colectividad, que en forma específica actúa mediante la postura democrática de representatividad del cuerpo electoral que clama por una voz que sea portadora de su voluntad popular.

Desprendida de esta búsqueda de participación en los asuntos organizadores del Estado, nace la figura jurídico-política del Parlamento en la Inglaterra Medieval, estableciéndose a la postre dentro de un régimen constitucional (liberal), luego de la revolución Industrial en Francia y la Declaración de los Derechos del Hombre y del Ciudadano de 1789. A diferencia de la generación inglesa, Francia instaura su posición como un mecanismo formal contra del monarca, conservando a la vez la esencia de aparición ante el Estado y los poderes que en él interactúan como motor organizacional.

A la par de la creación de este órgano representativo y con la finalidad de proteger la integridad del cuerpo electoral como manifestación de voluntad soberana, motor y esencia misma del Estado, nacen determinadas figuras jurídicas de orden constitucional que establecen una protección fundamental para la manutención del sistema gubernativo y para la desconcentración misma del poder del Estado, interactuando en su conformación como mecanismos de pesos y contrapesos al absolutismo y centralización del poder, ello en apreciación del Principio de División de Poderes.

Estas figuras jurídicas ${ }^{2}$ que han de servir como herramienta básica en el desempeño de la labor del Parlamento, y que han sido creadas en miras de lograr un equilibro político en la operatividad del Estado, han sido contempladas por la constitución como instituciones jurídicas que sirven de protección a éste, contra de eventuales persecuciones no sólo jurídicas, sino -las más de ellas- de corte político, frente a las manifestaciones ${ }^{3}$ que $\operatorname{los}$ parlamentarios puedan realizar del sistema gubernativo en turno, así como respecto de los distintos órganos de funcionamiento estatal.

Estas protecciones de orden constitucional que existen desde la creación misma del parlamentarismo inglés ${ }^{4}$, han sido conocidas con el nombre de inviolabilidad e inmunidad parlamentaria, dentro de la doctrina que se denomina de la freedom of speech y la freedom from arrest. Ambas instituciones controlaban la protección parlamentaria respecto a la libertad de expresión en los asuntos del Estado y la prohibición de arresto por conductas de orden civil.

La inviolabilidad e inmunidad parlamentarias han sido foco de múltiples y constantes confrontas jurídicas en torno a su idoneidad y utilidad, llegando a convertirse en

\footnotetext{
${ }^{1}$ Así por ejemplo en HELLER, Hermann, Teoría del Estado. Teoría política, ed. 39, Edit. Porrúa, México, 2005.

${ }^{2}$ Cabe señalar como se hará infra, que las mismas pueden denominarse y con justa razón figuras de orden político más que jurídico.

${ }^{3}$ Manifestaciones que, a decir de Pedro de Vega en comento a Schmitt, resultan ser el espíritu del parlamentarismo. DE VEGA GARCÍA, Pedro, "El Principio de publicidad parlamentaria y su proyección constitucional", en REP, $\mathrm{N}^{\circ} 43$, enero-febrero 1985, España, pp. 45-65.

${ }^{4}$ Se establece que se han dado aparentemente, puesto que parte de la doctrina parlamentaria ha establecido que el parlamento tal como hoy se establece no tiene nacimiento en Inglaterra, sino que se da en Francia dentro del siglo XVIII.
} 
impedimentos jurídico-políticos para la impartición de justicia, en privilegios que se contrapone al principio de Igualdad ante la ley que propugna el Estado de Derecho, más no necesariamente así perceptible en el Estado Democrático. Situación que conlleva a que estas figuras de protección, conjuntamente con la institución del aforamiento, hayan sido mal usadas por la sociedad política al grado de representarse como privilegios más allá de la función pública concretamente en ámbitos particulares, como un uso desmedido de ellas incurriendo en actividades que salen fuera del espectro constitucional, convirtiendo a sus poseedores en personas impunes ante la ley y facilitando con ello la comisión de actividades delictivas sin que exista repercusión legal alguna sobre de ellos. Por medio del aforamiento se ha llegado al extremo de proteger no solo a los representantes estatales, sino también a sus cómplices en hechos ilícitos.

Al ser considerados los representantes de la sociedad como sujetos que gozan de una posición privilegiada ante la ley y ante sus propios electores, se ha producido inevitablemente un discurso iracundo por parte del cuerpo electoral que pugna por la desaparición de esos permisos para delinquir que han sido representados sobre la base de las inmunidades parlamentarias respecto de su uso mal intencionado en miras a la impunidad y la corrupción.

Los problemas que presentan estas instituciones son comunes en el ejercicio político de México y España, países en donde el Parlamento se corresponde en obligaciones y prerrogativas. De forma semejante, en ambos territorios los miembros de esta institución suelen padecer de la animadversión social que los identifica como corruptos y delincuentes ${ }^{5}$ protegidos por la ley. De esta suerte, la presente investigación es resultado de un estudio comparativo entre España y México en lo que refiere a la actualidad de las figuras de inmunidad, inviolabilidad y aforamiento.

En un primer momento caracterizamos dichas figuras jurídicas a razón de los antecedentes medievales y modernos, para luego analizar sus implicaciones en los sistemas democráticos de los países propuestos, haciendo hincapié en los obstáculos que encuentran, tanto en su interpretación como en su uso. Finalmente se ha tratado de establecer la pertinencia de las protecciones parlamentarias a la luz de los principios de División de Poderes, Proporcionalidad y Representatividad.

\section{DEL PARLAMENTO Y SUS INSTITUCIONES DE PROTECCIÓN}

\section{El parlamento medieval inglés}

Tratar de establecer un diálogo respecto a temas de cauce jurídico y político resultan siempre controvertido, no sólo por las diversas posturas en pro o en contra de las que se

\footnotetext{
${ }^{5}$ Discurso que, si bien es pregonado socialmente, no implica que per se la condición de parlamentario implique una calidad delictiva en el sujeto político, más la extensión injustificada del alcance material de las inmunidades, ha hecho ver en el discurso político a los representantes como sujetos intocables ante la ley.
}

Аnи Fac Der UDC, 2018, 22:418-446 
pueda dar cuenta, sino por la misma naturaleza de poder y control que se instauran en el ejercicio estatal. No resulta extraño el hecho de que la formación misma de lo que hoy día se conoce como Parlamento y sus respectivas prerrogativas y/o mecanismos de protección se vuelvan motivo de arduas confrontaciones y opiniones disímiles en su apreciación y ejercicio.

Una primera discusión surge cuando de ubicar el nacimiento del Parlamento se trata, pues algunos especialistas se inclinan por la Inglaterra medieval, ${ }^{6}$ y otros tantos por la Francia liberal. ${ }^{7}$ Los primeros identificando que en la Edad Media inglesa el Monarca era el único titular de poder y por tanto soberano de la nación, no había opinión que pudiese importar sin la plena voluntad de éste. El Monarca era el único centro de poder sobre el que residía la omnipotencia de la sociedad, más sólo aquella que representaba un fiel súbdito en términos monetarios, residiendo la representación popular en el consejo que el mismo Monarca establecía sin mayor opinión que la de acatar sus decisiones, sirviendo los mismos sólo como portavoces de la voluntad indiscutible del Rey.

Es la recisión económica propia del medievo inglés lo que ocasiona que el monarca incapaz de mantener financieramente el coste ocasionado por su ejército, se vea en la necesidad de adoptar medidas externas para lidiar con la crisis económica que colisionaba el orden político del momento ${ }^{8}$. Medidas que llevan a la regeneración del consejo consultivo del Monarca obligándose a admitir en el mismo a "representantes de los únicos entre sus súbditos capaces de pagar impuestos", es decir, burgueses convertidos ahora a la Curia Regis en el Parlamento Inglés. A partir de esta colisión política la burguesía de la sociedad inglesa comienza a formar parte operativa dentro de la toma de decisiones del reino, ya con voz propia dentro del consejo y no como meros espectadores de las proposiciones del Monarca. En este punto los especialistas ${ }^{10}$ identifican el nacimiento de las franquicias más conocidas del parlamentarismo medieval: la freedom of speech y el freedom from arrest, concretamente lo que tendría que entenderse como libertad de expresión y garantía de no ser aprisionados por deudas de orden civil. ${ }^{11}$

Este acontecimiento histórico ha sido uno de los postulados de mayor algidez respecto a la fundamentación de la creación del parlamento y de las figuras jurídicas que nacen como formas de protección especial de éste, a la fecha siendo el cimiento jurídico con el que la modernidad da cuenta de la protección parlamentaria vía inviolabilidad e inmunidad ${ }^{12}$. Sin embargo, es importante señalar que el modelo medieval es distante del actual en tanto el

\footnotetext{
${ }^{6}$ Así, por ejemplo: May, Fraga, Carro, Pérez Serrano, Esmein-Nezard, Lucas Murillo, etc.

${ }^{7}$ Así, por ejemplo: Fernández-Miranda, Emilio Recoder de Caso, Bockelmann, Eloy García, BarthélemyDuez, etc.

${ }^{8}$ Cfr. GARCÍA, Eloy, Inmunidad Parlamentaria y Estado de Partidos, Edit. Tecnos, España, 1989, pp. 22 y 23.

${ }^{9}$ Ibid.

${ }^{10}$ Esmein-Nezard, Barthélemy-Duez, Biscaretti di Ruffìa, Pérez Serrano, Fraga, Carro, etc.

${ }^{11}$ GARCÍA, Eloy, op. cit., p. 23.

${ }^{12}$ Así por ejemplo en: I. Loveland, Constitutional Law, Administrative Law and Human Rights (A Critical Introduction), 4. ${ }^{\mathrm{a}}$ ed., Oxford-New York, Oxford University Press, 2006, p. 264.
} 
primero constituía únicamente una salida a causas de tipo civil, mientras que el segundo se ha extendido a causas penales. ${ }^{13}$

Desde esta postura la división de poderes se observa en todo su esplendor, pues si bien se habla de la necesidad representativa del parlamento, no puede dejarse de lado que a la par de este poder existía de igual forma el poder de enjuiciamiento real, mediante el cual también se gozaba de ciertas inmunidades. En sentido concreto puede entenderse como independencia del poder tanto monárquico como parlamentario, colisionando por tanto en la apreciación de un poder judicial. ${ }^{14}$

En estos términos el parlamento medieval se presentaba y actuaba únicamente como un comisionado jurídicamente vinculado ${ }^{15}$ a las instrucciones del burgo que lo propone, de aquellas personas que los posicionaban en tal lugar y no así como un auténtico representante político de la totalidad del cuerpo social. Al ser un portavoz de cierta parte de la colectividad en vía de un mandato representativo ${ }^{16}$, se hizo necesaria la aparición práctica de ciertos derechos singulares que garantizaran la libertad de opinión ante el Monarca dentro de las decisiones de la sociedad, sin las cuales en otro momento habrían ocasionado fácilmente una sentencia condenatoria contra de las manifestaciones vertidas en contraposición a las del Rey.

Por tanto, estas inmunidades o derechos singulares de los que se habla, surtían el efecto de llevar ante el monarca las instrucciones de la burguesía por vía de sus encomendados, que como bien lo señala Eloy García:

Su misión consistía, por tanto, no en participar en la formación de una voluntad colectiva inexistente, sino en transmitir fielmente, de manera casi literal, las opiniones de sus comitentes, de modo que perseguirlo judicialmente a causa de sus comportamientos parlamentarios, equivalía, poco más o menos a negar, al burgo o corporación que lo había enviado, el derecho a formular proposiciones y a emitir votos en materia que le afectaban directamente, derecho que según el viejo aforismo <<no taxation without representation>>, se consideraba como una justa contraprestación al deber de pagar impuestos. ${ }^{17}$

\footnotetext{
${ }^{13}$ Respecto al tema de la "civil arrest", véase también: BRADLEY, A. W., y EWING, K. D., Constitutional

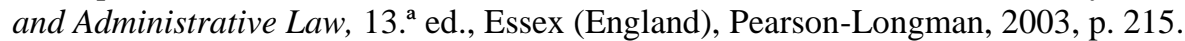

14 "En la historia política y constitucional inglesa se colocaron, desde un principio, las deliberaciones y votaciones de las Cámaras bajo el régimen del secreto, en una doble perspectiva: en primer lugar, impidiendo al público el acceso a los lugares de sesiones, y, en segundo término, prohibiendo a los diputados, o a personas ajenas al Parlamento, publicar o dar noticias de los contenidos de los debates sin la debida autorización". DE VEGA GARCÍA, Pedro, "El Principio de publicidad parlamentaria y su proyección constitucional", op. cit.

${ }^{15}$ Así en: GARCÍA, Eloy, op, cit., pp. 45-46.

16 "La imposibilidad de participar masivamente en la discusión y decisión del proceso político, que es lo que condiciona la representación parlamentaria, plantea un dilema de notables e importantes consecuencias. Por un lado, la mecánica de la discusión y el descubrimiento de la verdad contrastando opiniones, ajenas, exige la libertad de quien discute. De ahí la justificación del mandato representativo en el parlamentarismo moderno. Si la esencia de la política parlamentaria es la deliberación, y habida cuenta de que la deliberación no es posible bajo la forma del mandato imperativo, el mandato representativo constituye una exigencia ineludible del sistema". Ibidem, p. 56.

${ }^{17}$ Ibidem, pp. 26 y 27.
} 
La inmunidad en términos de freedom of speech, es entendida no como una defensa o garantía judicial del parlamentario frente a la presencia del soberano, sino más en el sentido de un privilegio que en forma personal otorgaba el monarca a aquellos grupos sociales que gozaban del derecho a emitir opiniones de consulta para los asuntos del reino. Primeramente garantizaba que las opiniones vertidas en el consejo habrían de ser escuchadas y consideradas al momento de emitir las decisiones pertinentes a los asuntos sociales, luego, otorgaba la seguridad de que las opiniones establecidas por los parlamentarios no serían utilizadas en su contra en forma legal para amedrentar a las personas que las transmitían como medio de amenaza penal.

De esta manera, "el orden político medieval, como cualquier otro de esta época, desconoce los supuestos básicos en que se asienta el concepto moderno de inmunidad"18. Como defiende Eloy García dos son las razones por las que históricamente aparece la inmunidad parlamentaria:

$>$ Postura que se sitúa respecto a los privilegios de la historia medieval inglesa ${ }^{19} ; \mathrm{y}$,

> Postura que desconociendo a esta primera, sitúa el concepto inmunidad -al menos a su actual percepción-, en atención a la revolución francesa, misma que se difunde por todo Europa para el siglo XIX. ${ }^{20}$

Si bien es cierto que la fundamentación con la que da cuenta el antecedente medieval sitúa al parlamento en tintes diversos a los actualmente concebidos, es preciso que demos crédito al mismo por ser el momento que denota por vez primera el privilegio de la inmunidad como medida de protección para la libertad de expresión ante los asuntos políticos de organización estamental, ya bien ante la presencia de un rey o ante la de un poder ejecutivo dentro del cual recae el privilegio de direccionamiento social.

\section{El parlamento herencia de la Revolución francesa}

La inmunidad parlamentaria que se desprende de la Revolución francesa - específicamente a partir del decreto de 20 de Junio de 1789- es la que más se compagina a la institución jurídica de la actualidad. Precisamente en Francia desde 1789 con la Constitución del Tercer Estado, se incorpora rotundamente en su arsenal jurídico a la inmunidad por vía de la inviolabilidad parlamentaria. Siguiendo a Barthélemy, dicha figura perseguía sin más

\footnotetext{
${ }^{18}$ GARCÍA, Eloy, op. cit., p. 27, citando a SURLESE, Laura, Il Re e i Lords nel Parlamento medievale inglese, cit. Cap. VIII, p. 27.

${ }^{19}$ En referencia a la defensa de esta tesis del nacimiento históricamente justificado de la inmunidad parlamentaria se tiene entre otros a May, Anson, Pérez Serrano, Fraga, Carro, etc.

20 Para mayor claridad y ejemplificación de ello, véase BOCKELMANN, Die Unverfolgbarkeit der Abgeordneten nachdeutschen Immunitätssrecht, Gotinga, 1951; FERNÁDEZ-MIRANDA y CAMPOAMOR, Alfonso, "Origen histórico de la inviolabilidad e inmunidad parlamentaria", en Revista de la Facultad de Derecho, Universidad Complutense, № monográfico 10, 1986, pp. 176 y ss; RECODER DEL CASO, Emilio, "Comentario al Artículo 71 de la Constitución", en Comentarios a la Constitución dirigidos por Garrillo Falla, Madrid, 1987.
} 
transferir a las Asambleas representativas del liberalismo constitucional una parte de los beneficios del viejo axioma absolutista: the king can not do wrong. $^{21}$

A diferencia del sistema inglés ya referido, la inmunidad en Francia se concentra en la figura del arrest, dirigido tendenciosamente a las prácticas de corte penal por parte de los parlamentarios, con la precisión de que exigía la autorización de la Asamblea para procesar a uno de sus miembros. Por su parte, la inviolabilidad se mantuvo bajo los términos de freedom of speech.

Fernández-Miranda se aleja de los privilegios medievales al referirse al antecedente inmediato de la inmunidad ${ }^{22}$, en su lugar señala a la Constitución francesa de 1791. Para el mismo autor, los fundamento y naturaleza son distintos, más bien siendo una suerte de protección para el Parlamento que consiste en impedir que sea controlado por el resto de los poderes del Estado, que surge "como fruto de un enfrentamiento histórico concreto entre un Parlamento revolucionario que se siente en peligro y un ejecutivo y un judicial emanación directa de la voluntad del rey", 23

Esta consolidación en las percepciones de lo que se entiende por inviolabilidad e inmunidad resultan ser el eslabón indispensable dentro de la teoría de las prerrogativas parlamentaria como protecciones al sistema gubernativo del Estado Democrático de Derecho. Teniendo como principal fundamento del derecho de libertad de expresión a la inviolabilidad piedra angular que protegerá el auténtico ejercicio político del parlamentario en pro de su libre opinión y emisión de voto, mientras que por lo que hace al ejercicio externo como medio de protección extraparlamentaria a la libertad de expresión se establece la protección de no ser arrestado por causas criminales salvo el caso de flagrante delito.

En la estructura organizacional de la Francia revolucionaria se aprecia claramente una transición del poderío del Monarca como soberano, a la soberanía entendida como la Nación. ${ }^{24}$ Se enaltece por vez primera el principio de soberanía nacional que sustraía al rey el poder absoluto de orden unipersonal, para situarlo en forma colectiva dentro de la nación. Pedro de Vega se refirió a esto de la siguiente manera:

Al ser la Nación un ente abstracto, que sólo puede expresar su voluntad a través de representantes, la potestad constituyente sólo podrá actuarse a través del mecanismo de la representación. El poder constituyente deja de ser el poder en el que el pueblo directamente

\footnotetext{
${ }^{21}$ BARTHÉLEMY, Joseph y DUEZ, Paul, Traité de Droit Constitutionnel, Dalloz, Francia, 1933, p. 569.

22 Véase para mejor explicación: FERNÁDEZ-MIRANDA y CAMPOAMOR, Alfonso, "Artículo 71. Inmunidad e Inviolabilidad Parlamentarias", en Comentarios a las Leyes Políticas, Dirigidos por Oscar Alzaga, Edit. Edersa, España, 1989;

"La Inmunidad Parlamentaria en la práctica de la II República y de las Cortes Constituyentes", en REOP, $\mathrm{n}^{\circ}$ 47, 1977; y,

"Origen histórico de la inviolabilidad e inmunidad parlamentaria", en Revista de la Facultad de Derecho, Universidad Complutense, $\mathrm{N}^{\circ}$ monográfico 10, 1986.

${ }^{23}$ FERNÁDEZ-MIRANDA y CAMPOAMOR, Alfonso, "Origen histórico de la inviolabilidad e inmunidad parlamentaria", en Revista de la Facultad de Derecho, Universidad Complutense, No monográfico 10, 1986, pp.176 y ss.

${ }^{24}$ Vid. CARRÉ DE MALBERG, Raymond, Contribución a la Teoría General del Estado, Edit. Dalloz.
} 
participa, como titular indiscutible de la soberanía, para convertirse en el poder de las Asambleas, en el que la nación delega sus competencias. ${ }^{25}$

En el proceso revolucionario francés la soberanía cambió de manos, en términos de absolutismo. ${ }^{26}$ Pues si bien el absolutismo monárquico había sido derrocado, tomó su sitio un absolutismo ejercido por la Asamblea, confundiéndose con la Nación en sí y no como un órgano representativo de ella. Sobre ello, Bousnard ha adelantado que un Parlamento así se siente soberano y ocupa una posición de mando respecto a los demás órganos del Estado, quienes se subordinan ante él. En este sentido, ha postulado que se debiese evitar tal confusión, de lo contrario nada impediría que la Asamblea usurpara los derechos de la misma nación ${ }^{27}$, en un juego indiscutible de absolutismo al puro estilo del Monarca.

La primera incursión de la inmunidad parlamentaria en contenidos actualmente aceptables, se deja de lado respecto a lo pugnado por el Constituyente del Decreto de 21 de junio d 1789, que concebía al término inviolabilidad, única y exclusivamente como institución protectora del Diputado frente al poder estatal y no así frente al cuerpo electoral. Concepción que el sistema representativo liberal no llegó a consolidar, tergiversando tal mandato, atribuyendo a tal inmunidad la finalidad de garantizar la naturaleza política y no jurídica, en la relación representante-representado. Con lo cual se evitaba contundentemente, que los electores pudieran exigir judicialmente al representante las motivaciones de su comportamiento. ${ }^{28}$ Por tanto, se habla de una inmunidad entendida en contraposición al argumento de la División de Poderes como estandarte fidedigno del Estado Democrático Constitucional.

Ante este panorama la inmunidad se posiciona como una prerrogativa protectora del Parlamento y como una prerrogativa en sentido singular ${ }^{29}$ que se establece de igual forma

${ }^{25}$ DE VEGA GARCÍA, Pedro, La Reforma Constitucional y la Problemática de Poder Constituyente, Edit. Tecnos, España, p. 32.

${ }^{26}$ En contraposición a esta libertad de representación parlamentaria que se ve equivocada, señala Constant que: "Del mismo modo, los pueblos, que con el objetivo de gozar de la libertad que les conviene recurren al sistema representativo, deben ejercer una vigilancia activa y constante sobre sus representantes para ver si cumplen exactamente con su encargo y si defraudan a sus votos y deseos. CONSTANT, Benjamin, "De la libertad de los antiguos comparada con la de los modernos" (1819), Del espíritu de conquista. De la libertad de los antiguos comparadas con la de los modernos, Madrid, 1988, p. 90; Cita en: RUIPÉREZ ALAMILLO, Javier, Libertad Civil e Ideología Democrática. De la conciliación entre democracia y libertad a la confrontación Liberalismo-Democracia, IIJ UNAM, México, 2008, p. 49.

${ }^{27}$ Archives Parlamentaires, première série, t. VIII, París, 1963, p. 579. Véase al respecto; GARCÍA, Eloy, op. cit., p. 31.

${ }^{28}$ En atención a la dicotomía liberalismo y democracia, en que la libertad individual se vuelve en una libertad política que equivoca el parlamento en esta relación representante-representado, cabe señalar como lo hace Ruipérez en cita a Constant, que los ciudadanos en ningún momento pueden abandonar definitivamente los asuntos políticos y dejarlos en manos de los representantes, pues el sistema representativo de elección parlamentaria, no "[...] garantiza que sea la voluntad de los representados la que se convierta en ley." $C f r$. RUIPÉREZ ALAMILLO, Javier, op. cit., p. 49

29 "La inmunidad fue concebida originariamente de acuerdo con la teoría clásica de la representación, como una protección del parlamentario (del Parlamento en último término, pero también del parlamentario) frente a las agresiones del ejecutivo". RUBIO LLORENTE, Francisco, "Parlamento y representación política", en Primeras Jornadas de Derecho Parlamentario, Madrid, 1985, p. 157. 
para el parlamentario en su individualidad, capaz no sólo de contrarrestar a los demás poderes del Estado, sino incluso de generar una auténtica irresponsabilidad tanto jurídica como política del parlamentario respecto a sus representados ${ }^{30}$, olvidando rotundamente que la finalidad de la inmunidad "está destinada a mantener al Diputado el status de persona privada insertada en público también en el plano parlamentario"31.

Son dos los argumentos que explican el sentido de la inmunidad parlamentaria dentro de su captación derivada del constitucionalismo del siglo XVIII:

$>$ La primera que se erige desde la perspectiva de la relación entre representantes y representados, para la cual, la inmunidad es una consecuencia más de la independencia del parlamento, que permite llevar hasta sus últimos extremos el principio de la irresponsabilidad jurídica del diputado respecto de su elector. ${ }^{32} \mathrm{Y}$,

> La segunda de ellas, desde la perspectiva propia de la institución parlamentaria, provista como que la inmunidad cumple también con la finalidad de garantizar la total y absoluta libertad de palabra del representante individual ${ }^{33}$, en el mayor sentido del goverment by talking. ${ }^{34}$

La presencia de este parlamento liberal instituye una doble finalidad de la inmunidad; 1) como Derecho Objetivo del parlamento en ocasión de órgano constitucional de representación; y, 2) como Derecho Subjetivo perteneciente al parlamentario individual como expresión de su voluntad. Que como bien señalara Eloy García, en cita a Pedro de Vega, "se trataría de recordar que el concepto jurídico de inmunidad descansa sobre un substrato histórico para el que tan importante es la defensa del Parlamento-corporación como garantizar la libre formulación y expresión de la voluntad del representante individual". 35

\section{INVIOLABILIDA E INMUNIDAD}

En el campo doctrinario las garantías de inviolabilidad e inmunidad del Parlamento han producido las más álgidas confrontas. Su significación, alcances, funciones y finalidades reconocidas como mandatos constitucionales son el motivo. Ambas se sitúan indiscutiblemente en la operatividad diversa del Derecho ordinario - de aquel derecho que corresponde a la totalidad de la sociedad- $y$, como lo hemos señalado, resultan necesarias para el adecuado funcionamiento organizacional de un Estado que se diga ser democrático y de Derecho.

\footnotetext{
${ }^{30}$ Por tanto, esta teoría de la soberanía parlamentaria, hace observar a la inmunidad, como un Derecho Subjetivo del parlamentario singular, situando al Bien Jurídico Tutelado por la prerrogativa, no sólo al órgano representativo, sino al representante en cuanto persona individual.

${ }^{31}$ HABERMAS, Jürgen, Historia y Crítica de la opinión pública, Barcelona, 1981, p. 325.

${ }^{32}$ GARCÍA, Eloy, op. cit., p. 47.

${ }^{33}$ Ibidem, p. 48

${ }^{34}$ La palabra actúa como medio y forma del parlamento. Para éste, las libertades de palabra, reunión y de discusión, no son tan sólo útiles y convenientes, sino instituciones vitales para el constitucionalismo liberal

${ }^{35}$ GARCÍA, Eloy, op. cit., p. 61.
} 
Para el caso del Estado mexicano las inmunidades no operan como conformación constitucional del sistema normativo, más ello no ha significado que tanto la doctrina como la jurisprudencia hayan realizado una suerte de interpretación que posiciona a ésta en el campo de acción procesal como garantía parlamentaria. Por tanto, habremos de dar por sentado que ambas figuras — inmunidad e inviolabilidad - son igualmente apreciables y operantes en México y España.

En estricto sentido, la inmunidad e inviolabilidad han significado para los ordenamientos constitucionales un estandarte de legalidad del Estado democrático de Derecho, sin duda como mástil del principio de división de poderes como derecho fundamental de la nación soberana. Definir estas garantías exige la mayor prudencia, pues los límites entre ambas suelen ser mal entendidos $\mathrm{y}$, por consiguiente, confundidos, llegándose al extremo de situarlas con la misma funcionalidad y finalidad. Para el derecho español ambas figuras resultan ser por demás conocidas y diferenciadas, pero han sido utilizadas sin las precisiones técnicas necesarias, posicionándoles genéricamente en el mismo término de inmunidad.

En sentido amplio, debe entenderse que la inmunidad parlamentaria es un derecho inherente a la condición de parlamentario, en virtud de la cual se le otorga al representante una cierta protección respecto a las acciones judiciales que se le pretendan incoar en su contra, ya los órganos estatales o bien los particulares. ${ }^{36}$ Indemnidad que variará en su sentido respecto de la que se trate, ya como inviolabilidad, o bien como inmunidad en stricto sensu.

La inviolabilidad se constriñe a ser una garantía que se encarga de salvaguardar las actuaciones, opiniones y votos que los representantes parlamentarios emitan en el pleno ejercicio político de sus funciones. Actuaciones que en ningún momento podrás ser consideradas como hechos constitutivos de delito $\mathrm{y}$, en consecuencia, los mismos de ninguna manera podrán ser impugnables en sede judicial.

En estricto sentido, la inviolabilidad consiste en la salvaguarda constitucional que tiene por finalidad el impedir que el parlamentario sea sujeto de arresto por autoridad alguna, o bien vinculado a juicio o encausado por actuaciones realizadas al margen de su función legislativa, sin que para ello pueda mediar con antelación la previa autorización de la Cámara a la que pertenezca, salvo en aquellos casos que el parlamentario sea aprehendido en flagrancia de la comisión de un hecho que la ley señale como delito.

La inmunidad resulta ser un complemento garantista de la inviolabilidad, máxime en aquellas circunstancias en las que el legislador ha realizado actuaciones fuera de su recinto parlamentario que puedan o no pertenecer a sus funciones representativas. La inviolabilidad sólo protege la actividad pública del parlamento, dentro de la cual, a decir del sistema

\footnotetext{
${ }^{36}$ BARTHÉLEMY-DUEZ, Traité de droit constitutionnel, p. 565; PORTERO, Inviolabilidad e inmunidad parlamentarias, Málaga, 1979; GÓMEZ BENÍTEZ, "La inviolabilidad e inmunidad parlamentarias", en Rev. F. Derecho, $\mathrm{n}^{\circ}$ 64, 1982.
} 
liberal clásico, se engloban sólo aquellas funciones tendentes a la conformación de la voluntad del parlamento.

\section{Naturaleza, finalidad y efecto}

Ambas instituciones jurídicas se instituyen como garantías, con la concreta diferencia que la inviolabilidad dispensa al parlamentario una protección de fondo, es decir, simboliza una garantía de irresponsabilidad jurídica como un derecho de naturaleza sustantiva por las opiniones manifestadas en el ejercicio de sus funciones. ${ }^{37}$ Sin ésta, el ejercicio de las funciones parlamentarias podrían resultar mediatizadas y frustradas y no podría existir la formación de la voluntad del parlamento.

En el contexto mexicano la inviolabilidad dispensa al legislador una protección de fondo, absoluta, llevada al grado de irresponsabilidad perpetua en tanto sus beneficios no están sujetos a periodo alguno. Prácticamente sitúa al parlamentario en una posición de excepción en todas aquellas circunstancias en que éste ejercite su función de representante público, pues automáticamente opera una derogación, es decir, una pérdida de vigencia y eficacia de los preceptos constitucionales que imponen a los poderes públicos el deber de responder a sus propios actos — aunque los consideren difamatorios - , lo que garantiza a todos los ciudadanos una tutela efectiva de sus derechos e intereses legítimos. ${ }^{38}$

Al igual que en el panorama mexicano, para el derecho español la inviolabilidad ocasiona una derogación normativa y, por consiguiente, una pérdida de la vigencia y eficacia de los preceptos constitucionales que impone a los poderes públicos el deber de responder de sus propios actos y de aquellos que garantizan a todos los ciudadanos mediante la tutela efectiva de sus derechos e intereses legítimos, obligando al gobierno y a los particulares a soportar la difamación parlamentaria "sans avoir aucun moyen juridique de se défendre contre celle-ci”. ${ }^{39} \mathrm{Al}$ respecto de la referida posición de excepción, Eloy García la considera como el logro más preponderante de la inviolabilidad parlamentaria alconvertir al diputado [...], en un fugitivo del Derecho, lo que, dicho sea de paso, significa y supone la quiebra más radical y profunda que imaginarse pueda de uno de los principios medulares sobre los que se levanta el edificio del Estado constitucional: la total y absoluta juridificación de todas las actuaciones del Estado o, lo que es lo mismo, la conversión en jurídicas de todas las relaciones del poder". ${ }^{40}$

Este fenómeno parece dar validez a la expresión schmittiana consistente en el enfoque político del derecho como motivador del Estado en el entendido de que en "el Estado de Derecho, pese a toda su juridicidad y normatividad, sigue siendo un Estado y contiene siempre otro elemento específicamente político"41. Lo anterior no anula las influencias

\footnotetext{
${ }^{37}$ STC 243/1988, 19/10, FJ 3.B.

${ }^{38}$ T.A. 1a. XXX/2000, op. cit.

${ }^{39}$ BARTHÉLEMY-DUEZ, Traité de droit constitutionnel, op. cit., p. 565

${ }^{40}$ GARCÍA, Eloy, Inmunidad Parlamentaria ..., op. ci., p. 74.

${ }^{41}$ SCHMITT, Carl, Teoría de la Constitución, op. cit., p. 145.
} 
sociológicas del aparato constitucional que prima cada vez más que el mismo enfoque jurídico. Con ello la división de poderes se ha visto mermada por el hecho de ser un mero trasunto de división sociológica de poderes fácticos sobre la percepción de un Poder Político, un Poder Mediático y un Poder Económico. Se trata de un reflejo de una sociedad sociopolítica caracterizada por la percepción de dos centro de poder antagónicos: por un lado la sociedad civil que es representada por el "parlamento", y del otro las aristocracias tradicionales encaramadas en el aparato del Estado representadas en mayor medida por la clase política oligárquica. $^{42}$

En esta interpretación de la inviolabilidad se centra concretamente la mayor diferencia existente entre ésta y la inmunidad. Mientras la primera simboliza un óbice de legalidad en el margen conductual del parlamento, la segunda se traduce en garantía visible en sector procedimental, más no de quebrantamiento constitucional, en términos de irresponsabilidad que contraviene el principio de igualdad judicial, haciendo al parlamentario un sujeto impune exento ante la ley. Más al ser parte de la ejecución de la primera, aun cuando sea sólo como protectora de la misma, ello no le implica cierta parte de responsabilidad inconstitucional que se aprecia en la inviolabilidad, al menos en el exceso de su uso no necesariamente referido a actos políticos. La libertad del ciudadano y no la gloria del Estado es el principio inspirador del mismo Estado de Derecho. Si la inviolabilidad no fuese absoluta, sería el Poder Judicial quien definiera cuándo una opinión parlamentaria ha contribuido o no a la formación de la Cámara y con ello se daría una suerte de judicialización de la actividad parlamentaria que sería una presión externa sobre los parlamentarios. $^{43}$

La inmunidad stricto sensu se establece como una garantía de corte formal cuya finalidad consiste en congelar, retardar la eficacia del proceso judicial, fungiendo como una barrera de protección que obstaculiza el enjuiciamiento de un parlamentario, en tanto no se obtenga la autorización por parte de la Cámara para realizarlo. A diferencia de la inviolabilidad, ésta no quebranta el orden constitucional. En términos de Barthémely "l'inviolabilité concerne la prodúcere, l'irresponsabilité touche au fond". 44 La inmunidad se reduce a ser una prerrogativa de orden procesal que carece de contenido material, precisamente como una autorización que salvo los casos de delito flagrante deberá conceder el Parlamento, previo a toda detención o arresto o persecución judicial, que fuese tendente a desembocar en una privación de la libertad por encontrarse el parlamentario sujeto a un juicio de orden penal. No actúa como una institución de fondo pues no implica un prejuicio de la culpabilidad del sujeto determinado respecto al juicio de reprochabilidad que se le pretende incoar, sino más bien es una autorización cuya materia de estudio resulta ser la examinación fundada o infundada de los cargos reprochados.

\footnotetext{
${ }^{42}$ Así en la discusión de la sociedad del siglo XIX, en: KELSEN, Hans, Teoría General del Estado, 5ta ed., Edit. Coyoacán, México, 2015, pp. 333-340.

${ }^{43}$ CÁTALA I BAS, Alexandre, "La Inviolabilidad a la luz de la sentencia del TSJ del País Vasco de 5 de septiembre de 2003, (Caso del Diputado de H.B. Jon Salaberria)", en CortsADP, no 14, 2003, p. 166.

${ }_{44}$ BARTHÉMELY-DOUZ, Traité de droit constitutionel, op. cit., p. 570. Para tal caso, léase a la "inviolabilité" como inmunidad; y a la "irresponsabilité" como inviolabilidad.
} 
De esta suerte puede decirse que la inmunidad guarda en sí dos acepciones ${ }^{45}$; 1) De fondo o sustancial, que se refiere propiamente a la garantía constitucional de protección de freedom from arrest; y, 2) De contenido procesal, comprendida en la tipología de exención, como mecanismo de procedibilidad. Siendo esta segunda, la que en el Estado mexicano se refiere la práctica del fuero legislativo respecto a la declaración de procedencia como forma para despojar al parlamentario de sus protecciones, ante la posible comisión de un hecho delictivo.

En el constitucionalismo mexicano la garantía de inmunidad es mal interpretada principalmente porque no está contemplada en el texto constitucional. Lo que ha realizado el Estado mexicano para posicionar y poner en ejercicio la garantía de la inmunidad ha sido el situar a ésta en una triple percepción desde la interpretación de la Suprema Corte de Justicia de la Nación, por vía de la mutación constitucional ${ }^{46}$ que implica la "modificación no formal del ordenamiento constitucional; [...] cambios operados en el mismo conjunto normativo, sin seguir el mismo procedimiento de reforma de la Constitución" ${ }^{\text {"47 }}$ en estricto sentido desde la opinión de la Primera Sala:

$>$ Como sinónimo de la inviolabilidad, al señalar que, el interés a cuyo servicio se encuentra establecida la inviolabilidad o inmunidad legislativa es el de la protección de la libre discusión y decisión parlamentarias $[\ldots]^{48}$.

$>$ Como garantía propia de la inviolabilidad en el entendido de impedir que el parlamentario sea detenido sin previa autorización de la Cámara, es decir, como garantía de la garantía de inviolabilidad, respecto al freedom from arrest; $\mathrm{y}$,

$>$ Como requisito de procedibilidad, a la par de ser sino sinónimo de fuero legislativo, si de ser la razón de éste. Específicamente respecto a ser considerada desde la postura de inmunidad-autorización que simbolizaría la necesidad de autorización de la declaración de procedencia.

\footnotetext{
45 SAAVEDRA GALLO, Pablo, "Privilegios personales de carácter jurisdiccional y procesal en materia penal", en RUDP, n 0 0, 1988, p. 60.

${ }^{46}$ En referencia a la dicotomía de normalidad y normatividad en el proceso de cambio constitucional fuera del procedimiento de reforma, es decir, en el de mutación constitucional, Wong Meraz en cita a Heller menciona que: "[...] la Constitución normada no consiste nunca de modo exclusivo en preceptos jurídicos autorizados por el Estado, sino que, para su validez, precisa ser contemplada por elementos extra jurídicos, como la aceptación por parte de aquellos a quienes la norma se dirige y la observan. [...] los preceptos pueden sufrir una evolución gradual y, no obstante, permanecer inmutable el texto del precepto constitucional, a pesar de que su sentido experimenta una completa revolución.

Tal cambio del precepto jurídico se realiza gracias a los principios jurídicos cambiantes, que vienen a ser la puerta por la cual la realidad penetra a diario en la normatividad. Así se hace posible el permanente acoplamiento de la normatividad respecto a la normalidad, y puede, en esta forma, concebirse a la Constitución total del Estado como forma cuya existencia se desarrolla”. WONG MERAZ, Víctor Alejandro, Constitución Mexicana. Reforma y Mutación, Edit. Porrúa, México, 2010, pp. 141 y ss.

${ }^{47}$ Ibidem, p. 145.

${ }^{48}$ Así en: INMUNIDAD LEGISLATIVA. OBJETO Y ALCANCES DE LA GARANTÍA PREVISTA EN EL ARTÍCULO 61 DE LA CONSTITUCIÓN FEDERAL, 9ª́poca, Primera Sala, T.A. 1a. XXX/2000.

INMUNIDAD PARLAMENTARIA. CONSTITUYE UNA GARANTÍA DE ORDEN PÚBLICO INDISPONIBLE PARA EL LEGISLADOR, QUE DEBE INVOCARSE DE OFICIO POR EL JUZGADOR, $9^{a}$ Época, Primera Sala, T.A. 1a. XXVIII/2000.
} 
En el segundo punto parecen coincidir mayormente la posición española y mexicana en cuanto al sentido formal de la inmunidad y, en consecuencia, también en el tercero como condicionante de procedibilidad que para ambos ordenamientos constitucionales significa la inmunidad, en tanto no implica un límite contundente al ius puniendi, ni mucho menos a la exclusión de jurisdicción, sino sólo como un requisito que condiciona la aplicación procesal de la ley por la previa autorización de la Cámara.

La inmunidad queda configurada, al menos en el Estado Democrático de Derecho, como un mecanismo jurídico cuya finalidad estriba en impedir que los poderes constituidos alteren en la práctica el esquema material de distribución de competencias y el sistema formal de relaciones interorgánicas que en su día diseñara el titular del poder constituyente ${ }^{49}$, por consiguiente, como un instrumento de la división jurídica de poderes.

\section{Efectos en el caso español}

Para el caso español, la forma de actuar de la inmunidad parlamentaria debe entenderse como mecanismo de menor intensidad y duración al ser concebida como un requisito de procedibilidad de corte penal, a diferencia de la inviolabilidad que simboliza una plena irresponsabilidad.

Dentro del artículo 71.2 $\mathrm{CE}^{50}$ no se especifican los efectos de la denegación del suplicatorio que proviene del ejercicio de la inmunidad, más el artículo 754 de la Ley de Enjuiciamiento Criminal precisa el sobreseimiento de la causa como consecuencia de la denegación. ${ }^{51}$ Dispositivo legal que se desprende en forma correlacionada con lo establecido dentro del artículo 7 de la Ley de 9 de febrero de 1912, ${ }^{52}$ disposiciones normativas que llevan a la conclusión de la existencia del sobreseimiento libre. ${ }^{53}$

En España la inmunidad da pie a un doble efecto: 1) para el caso de que el suplicatorio sea concedido, la inmunidad será sólo un obstáculo procesal; 2) más para el caso en que el suplicatorio sea denegado, la inmunidad actúa como una condición objetiva de culpabilidad, radicando aparentemente tal conjetura en una calidad específica del sujeto activo, por normativo constitucional. Siguiendo a Martín de Llano, la concesión del suplicatorio transforma a la inmunidad en un simple obstáculo procesal, pero su denegación la convierte en una causa de exclusión de la pena. ${ }^{54}$

\footnotetext{
${ }^{49}$ Cfr. GARCÍA, Eloy, op. cit., pp. 96 y 97

${ }^{50}$ Constitución Española

${ }^{51}$ Artículo 754. Si el Senado o el Congreso negasen la autorización pedida, se sobreseerá respecto al senador o diputado a Cortes; pero continuará la causa contra los demás procesados.

${ }^{52}$ Artículo 7. Si el Senado o el Congreso denegase la autorización para procesar, se comunicará el acuerdo al Tribunal requirente, que dispondrá el sobreseimiento libre, respecto al Senador o Diputado. Si la autorización fuese concedida, continuará el procedimiento hasta que recaiga resolución o sentencia firme, aun cuando antes de dictarla fueren disueltas las Cortes a que perteneciere el Senador o Diputado objeto del suplicatorio. ${ }^{53}$ STC 92/1985, F.J. 5

54 MARTÍN DE LLANO, María Isabel, Aspectos constitucionales y procesales de la inmunidad parlamentaria en el ordenamiento español, Dykson, España, 2010, p. 144.
} 
Es precisamente la referencia a la ley de 1912 la que sitúa la mayor característica de la inmunidad para el caso español, aun siendo una ley "Pre-Constitucional" establece la base del enjuiciamiento criminal para el caso en que el parlamento deniegue en forma expresa o tácita el suplicatorio. Ello colisiona en un archivo definitivo del procedimiento penal sin la opción de que pueda reabrirse una vez terminado el mandato del representante, pues el efecto del sobreseimiento implica la imposibilidad material de persecución en términos de non bis in ídem. En este entendido, sería el Parlamento, el órgano encargado de declarar la irresponsabilidad jurídica del diputado, y en consecuencia de quebrantar la Constitución, en lo que a la autonomía Judicial se refiere, actuado éste como órgano enjuiciador y no legislativo. ${ }^{55}$ Por tanto, el sobreseimiento libre sería una extralimitación de la inmunidad parlamentaria. ${ }^{56}$

Con la denegación del suplicatorio y la aparición del sobreseimiento libre que sitúa a la acción penal en una suerte de cosa juzgada, la inmunidad deja de revestir un mero carácter procesal pasando a ocupar una postura sustantiva de carácter penal. En efecto, es una condición objetiva de punibilidad, lo que en forma injustificada ocasiona la desaparición de la responsabilidad penal correspondiente, con lo que la inmunidad extravasa la finalidad del instituto, ocasionando con ello una práctica que contraviene el orden constitucional. La autorización parlamentaria se convierte en su referente de denegación, en una carta de impunidad para el parlamentario encausado. ${ }^{57}$

Aunque en estricto sentido esta postura de la inmunidad derivada de la ley de 1912 pueda parecer objetivamente válida por la vigencia de los ordenamientos legales, resulta ser una disposición inconstitucional en virtud de lo signado por el numeral 24.1 de la CE, específicamente respecto al principio de tutela efectiva, a fin de no producir con ello un abuso mayor de derechos fundamentales respecto al estado de indefensión. Máxime mediante lo establecido en la $\mathrm{CE}^{58}$ en la disposición derogatoria en su apartado $3 .^{59}$ En el

\footnotetext{
${ }^{55}$ GARCÍA, Eloy, op. cit., pp. 80-81.

${ }^{56}$ Cfr. FIGUERUELO BURRIEZA, Ángela, "Derechos fundamentales y abuso de inmunidad", en Memorias del IV Congreso Iberoamericano de Derecho Constitucional, México, IIJ-UNAM, 1992, p. 212.

${ }^{57}$ MARTÍNEZ SOSPEDRA, Manuel, op. cit., p 286.

${ }^{58}$ Disposición derogatoria 3. Asimismo, quedan derogadas cuantas disposiciones se opongan a lo establecido en esta Constitución.

${ }^{59}$ Condición que pone en juicio el uso de la inmunidad parlamentaria como consecuencia de que se llegase a la creencia del parlamento como soberano, con lo que el principio de Supremacía Constitucional estaría en juego. Por tanto, se tendría que decir que la disposición normativa de la ley de 1912, es inconstitucional. A esta conclusión puede decirse, llega el Tribunal Constitucional en: STC 92/1985, de 24 de julio, FJ 5. "Para valorar si tales Autos, con el alcance visto, se oponen o no al art. 24.1 de la C.E., debe tenerse en cuenta que su fundamento último radica en la denegación de la autorización para procesar al Senador señor Barral acordada por el Pleno del Senado en 23 de noviembre de 1983. Acuerdo que este TC ha declarado nulo por Sentencia de 22 de julio del presente año; por ello resulta claro que tales Autos vulneran el art. 24.1 de la C.E. al hacer imposible en el futuro el ejercicio del derecho a la tutela judicial efectiva, sobre la base de entender que es aplicable el sobreseimiento libre por darse el presupuesto de hecho previsto en el art. 754 de la Ley de Enjuiciamiento Criminal, es decir, la denegación de la autorización para procesar adoptada por acuerdo del Senado, declarado nulo. En consecuencia, procede declarar la nulidad de tales Autos y retrotraer las actuaciones al momento en que la Sala Segunda del Tribunal Supremo acordó solicitar la autorización para procesar en forma de suplicatorio".
}

Anu Fac Der UDC, 2018, 22:418-446 
supuesto de aplicarse la inmunidad derivada de la ley de 1912, se estaría ante una práctica inconstitucional que ampara un parlamento soberano, negando en todo momento el Principio de Supremacía Constitucional, ocasionando el derrumbe del Estado Democrático Constitucional respecto a la autonomía e independencia judicial que prima en la división de poderes

\section{Efectos en el caso mexicano}

Entender la inmunidad en el Estado mexicano resulta ser controvertido en términos de lo que se ha venido sosteniendo a decir de la prerrogativa, pues en el constitucionalismo del país la inmunidad se ve traducida en el llamado Fuero Constitucional, con el entendido de ser igualmente un requisito de procedibilidad para poder detener o procesar a un legislador.

El texto original del artículo 61 de la Constitución de 1917 consagró únicamente a la inviolabilidad por las opiniones manifestadas. Hasta 1977 se adicionó un segundo párrafo a dicho artículo constitucional en el que se contempla la protección procesal o "fuero constitucional" de los parlamentarios respecto de los actos u omisiones que puedan generar una responsabilidad penal.

Resulta obvio que el trato de la inmunidad no viene dado por la propia Constitución, sino que es una norma secundaria la que le da vigencia en su ejecución. Se trata de la Ley Federal de Responsabilidades de los Servidores Públicos de 1982 que, conjuntamente con otros artículos constitucionales, hacen referencia a la declaración de procedencia, considerada esta última como la forma o procedimiento para superar la inmunidad parlamentaria o procesal en materia penal, expresamente las disposiciones del Artículo 111 Constitucional. ${ }^{60}$ Esta consideración pone en riesgo la estructura jurídico-política estatal al dejar al legislador ordinario la regulación y generación de un precepto constitucional, con lo que se pierde eficacia normativa convirtiendo al poder constituido en poder constituyente y violándose el principio Constitucional de Lex Suprema. ${ }^{61}$

Cabe señalar que es dentro del Reglamento de la Cámara de Senadores donde en forma contundente se utiliza la palabra inmunidad para referirse a las garantías constitucionales que establece el artículo 61 y 111 Constitucionales, específicamente dentro de su artículo

\footnotetext{
${ }^{60}$ Artículo 111. Para proceder penalmente contra los diputados y senadores al Congreso de la Unión, los ministros de la Suprema Corte de Justicia de la Nación, los magistrados de la Sala Superior del Tribunal Electoral, los consejeros de la Judicatura Federal, los secretarios de Despacho, el Fiscal General de la República, así como el consejero Presidente y los consejeros electorales del Consejo General del Instituto Nacional Electoral, por la comisión de delitos durante el tiempo de su encargo, la Cámara de Diputados declarará por mayoría absoluta de sus miembros presentes en sesión, si ha o no lugar a proceder contra el inculpado. Párrafo reformado DOF 10-08-1987, 31-12-1994, 22-08-1996, 02-08-2007, 07-02-2014, 10-022014, 29-01-2016.

${ }^{61}$ Cfr. Ruipérez Alamillo, Reforma vs. Revolución. Consideraciones desde la Teoría del Estado y de la Constitución sobre los límites materiales a la revisión constitucional, Edit. Porrúa, México, 2013; y, WONG MERAZ, Víctor Alejandro y CABANAS VEIGA, Manuel, "Los Derechos Sociales como límite de la Reforma Constitucional, un análisis desde su concepto y la teoría de la Constitución”, en Derechos Humanos. Realidades y Desafíos, Edit. vLex, México, 2017.
} 
6to, ${ }^{62}$ situación que no opera para el reglamento de los Diputados. Una segunda característica que diferencia a la inmunidad dentro del Estado mexicano es el requisito de procedibilidad en tanto faculta a la Cámara Baja (cámara de diputados) de conocer de la declaración de procedencia, con independencia de si ésta es signada contra un Diputado o un Senador.

Por último, el efecto contundente de la inmunidad respecto a la negativa de conceder la declaración de procedencia implica simplemente un efecto suspensivo sobre el ejercicio de la acción penal, en tanto dure el mandato del representante. La misma puede ser ejercida con toda fuerza y vigor al término del mandato, postulando en efecto a la inmunidad como un mero requisito de procedibilidad que, aun cuando en el ejercicio del poder se haga uso de los privilegios que la partidocracia establece para sus representantes, ${ }^{63}$ ello no implica que pueda afectarse el principio de igualdad y tutela efectiva, pues los efectos de ésta no son absolutos, sino sólo suspensivos temporalmente.

A diferencia del sistema español en donde puede operar el amparo para el caso de la denegación del suplicatorio, en México es prácticamente imposible, pues como mandato Constitucional se establece que la denegación de la declaración de procedencia es inatacable por otros medios de defensa, ${ }^{64}$ redacción que se refuerza aún más con lo establecido por la Ley de Amparo dentro de su artículo 61, fracción V. ${ }^{65}$

\section{AFORAMIENTO}

Dentro de la doctrina Constitucional el debate sobre las garantías que envisten al Parlamento ha sido un tema de constante discusión, en estricto sentido en cuanto hace a las garantías de inmunidad e inviolabilidad. Por su parte, el aforamiento no ha centrado mayor discusión al respecto que el que se suscita en ocasión del doble grado de jurisdicción,

\footnotetext{
${ }^{62}$ Artículo 6.

1. Durante el ejercicio de su encargo, los senadores tienen la inmunidad que establecen la Constitución Política de los Estados Unidos Mexicanos y las leyes. Dicha inmunidad inicia una vez que se rinde la protesta señalada en el artículo 128 de la Constitución y concluye el último día de ejercicio del cargo.

2. Los senadores son responsables por los delitos que cometen durante el tiempo en que ejerzan su cargo. Para que se proceda penalmente en su contra, deben cumplirse los requisitos, trámites y procedimientos que establecen la Constitución y la normativa aplicable. [...]

${ }^{63}$ Privilegios que se obtienen en forma interna dentro de cada grupo parlamentario que derivan directamente de la partidocracia en el ejercicio del poder, en donde por ser un miembro del mismo partido que ostenta la mayoría en la cámara, difícilmente se concederá el juicio de procedencia, incurriendo con ello, en una práctica no objetiva del mandato de representación y las repercusiones jurídicas que en forma individual pudieran llegar a presentarse fuera de los intereses democráticos del sistema partidista.

64 Artículo 111, párrafo 6, Constitucional: Las declaraciones y resoluciones de la (sic DOF 28-12-1982) Cámaras de Diputados (sic DOF 28-12- 1982) Senadores son inatacables.

${ }^{65}$ Artículo 61. El juicio de amparo es improcedente:

[...] V. Contra actos del Congreso de la Unión, su Comisión Permanente o cualquiera de sus cámaras en procedimiento de colaboración con los otros poderes que objeten o no ratifiquen nombramientos o designaciones para ocupar cargos, empleos o comisiones en entidades o dependencias de la Administración Pública Federal, centralizada o descentralizada, órganos dotados de autonomía constitucional u órganos jurisdiccionales de cualquier naturaleza;
}

Anи Fac Der UDC, 2018, 22:418-446 
implicando un discurso plenamente aceptado por razones ya de poderes constituidos y sus respectivas independencias y de retribución inmediata a las dos garantías que ex ante de ésta son apreciables.

Que el aforamiento este soslayado frente a las prerrogativas que le anteceden, ha implicado que los debates social y político se enaltezcan, máxime en la concepción moderna del Estado de Derecho y la aplicación del debido proceso, que se sitúa en específico desde la postura del principio de igualdad y el de recurso eficaz. En este punto nos referimos específicamente al caso español, en donde la garantía de aforamiento implica una calidad de jurisdicción especial a la del juez ordinario, situación que como ya se ha expresado supra, para el caso mexicano es distinto.

\section{Aforamiento en España}

El tema del aforamiento ha sido un constante en la discusión social y política para la sociedad española. Esto obedece a los excesos con los que se ha dado cuenta en la integración de casos criminales seguidos contra Diputados y Senadores. En dichos procesos se han visto inmiscuidos terceros que sin fungir siquiera como trabajadores estatales se ven igualmente cobijados por la garantía de jurisdicción por vía del principio de conexidad de la causa penal, lo que ha implicado la absorción de su decisión judicial a la par de los sujetos aforados. Al respecto, el artículo 71.3 CE establece que en las causas contra Diputados y Senadores es competente la Sala de lo Penal del Tribunal Supremo, situándose por tanto la juridicidad de juez ordinario en una instancia de orden constitucional, precisamente predeterminado por mandato constitucional para el caso de las causas penales seguidas contra aquellos.

Salvo el trato que da la ley de 1912, la LECriminal no regula la procedibilidad que en la realidad opera en el aforamiento, más tal supuesto se desarrolla concretamente en el artículo 57 de la LOPJ que establecen la forma de obrar de los jueces y magistrados que llegaran a la ocasión de instruir una causa penal en la que se vea inmiscuido algún miembro de las Cortes Generales. En este sentido, el aforamiento implica un reforzamiento indiscutible de las garantías de inviolabilidad e inmunidad, en el sentido de que si la inmunidad es un presupuesto necesario del aforamiento, y a la vez ésta es garantía de la inviolabilidad, el aforamiento resulta ser una garantía de las dos anteriores ${ }^{66}$, en términos de establecer la jurisdicción que ha de procesarles, en el caso de que sean perseguidos por acciones de orden penal.

El aforamiento consiste en una garantía traducida en la obligación legal que tiene el Poder Judicial, respecto a que las causas penales que sean instauradas contra de Diputados y Senadores no puedan ser conocidas por el juez natural u ordinario, sino que será el Tribunal Supremo, específicamente la Segunda Sala, quien será el único facultado para ello. A decir de Sospedra, esto implica una decisión del parlamento y por tanto una intromisión de

${ }^{66}$ Cfr. MARTÍNEZ SOSPEDRA, Manuel, op. cit., p. 355. 
poderes con lo que se vulnera el principio de división de poderes, actuando en forma contraria a garantizarlo. ${ }^{67}$

En sentido contrario, el aforamiento lejos de quebrantar la división de poderes clásica, lo enaltece, al configurar no sólo la independencia y autonomía del Parlamento, sino también la propia independencia y autonomía del Poder Judicial, que se establece como una garantía judicial en términos de no intimidación, presión a la que estaría sujeto un juez ordinario, no así un togado del Tribunal Supremo. La responsabilidad de procesar no recae en los presuntos operadores más vulnerables o débiles del enramado judicial, sino en los pilares fundamentales que establecen la oposición al poder parlamentario. ${ }^{68}$ La operatividad del Tribunal Supremo en las causas penales de los parlamentarios se deviene como un instrumento que garantiza la neutralidad de la función judicial. ${ }^{69}$

Instituyese de esta forma dentro del aforamiento la garantía del "juez natural"70 que, en mayor medida, implica la pugna política que parece confiar la necesidad de que los Diputados y Senadores en vista de la inminente repercusión social que su enjuiciamiento produce por virtud de la impunidad y la corrupción que sugiere el ejercicio del poder, se tenga un propio juez, mismo que sea legitimado socialmente por su capacidad de alejarse de los vaivenes de los estados de opinión y de la prensa, conservando con ello la imparcialidad y neutralidad, así como la protección de los derechos fundamentales del parlamentario $^{71}$ como sujeto social, que en caso contrario bien pudiesen verse inexistentes, no olvidando que al final del día la judicatura no es más que un órgano más de ejecución del poder estatal, a la par del parlamento. ${ }^{72}$

Por otro lado, el aforamiento implica un óbice al principio de doble jurisdicción, pues al menos en la práctica para los aforados el juicio penal es uniinstancial, en abierta

\footnotetext{
${ }^{67}$ Ibidem, p. 249.

${ }^{68}$ Como lo estimara preciso FERNÁNDEZ-MIRANDA, el aforamiento encuentra su justificación en que con esta garantía se "define, en principio, a los propios parlamentarios, garantizando la máxima solvencia en el enjuiciamiento. De otro modo se defiende también al propio Poder Judicial, haciendo recaer la responsabilidad de la sentencia, no sobre eslabones presumiblemente más débiles de la organización judicial, sino sobre el órgano supremo". FERNÁNDEZ-MIRANDA Y CAMPOAMOR, Alfonso, "Artículo 71. Inviolabilidad e inmunidad parlamentarias", en Comentario a las Leyes Políticas, O. Alzagar (dir.), Vol. VI, Madrid, 1989, p. 375.

${ }^{69}$ FERNÁNDEZ-VIAGA BARTOLOMÉ, Plácido, El Juez natural de los Parlamentarios , Civitas, Madrid, 2000, pp. 106-107.

${ }^{70}$ STC 22/1997, de 11 de febrero, FJ 7. Desde esta perspectiva, la Sala Segunda del Tribunal Supremo es, respecto de las acciones penales dirigidas contra Diputados y Senadores, "el Juez ordinario predeterminado por la Ley" a que se refiere el art. 24.2 C.E., esto es, aquél constituido con arreglo a las normas procesales de competencia preestablecidas, en este caso, por la Constitución misma en su art. 71.3. Predeterminación constitucional del órgano jurisdiccional competente que comporta el seguimiento de una distinta tramitación procesal de las causas contra Diputados y Senadores, que no se configura con ventajas especiales, ya que en este proceso es viable, excepcionalmente, la inexistencia de "un segundo grado jurisdiccional" (STC 51/1985, fundamento jurídico $3^{\circ}$ ), proceso distinto exigido por ese interés superior del Ordenamiento que es la independencia y el prestigio de las instituciones, imprescindible en el funcionamiento de todo Estado democrático.

${ }^{71}$ Ibidem, p. 35.

${ }^{72}$ Véase al respecto: KELSEN, Hans, Teoría del Estado, op. cit.
} 
contradicción con lo predispuesto en el artículo 14.5 del $\mathrm{PIDCP}^{73}$, mismo que a la luz del principio de recurso eficiente propio del debido proceso que debe imperar en todo Estado Democrático de Derecho, sitúa una clara desproporción de lesividad en la protección de los derechos de los parlamentarios. El mismo, en ocasión de reivindicar a las prerrogativas como la inviolabilidad y la inmunidad, se ha configurado como una justa contra-retribución ante el alcance desigual que en apariencia sitúan las dos anteriores. Por tanto, a decir de la STC 22/1997 (FJ 7) la finalidad que persigue el aforamiento es la de proteger la independencia institucional tanto de las Cortes Generales como del propio Poder Judicial frente a potenciales presiones externas o las que pudiese ejercer el propio encausado por razón del cargo político e institucional que desempeña.

\section{Aforamiento en México}

Como ya se ha mencionado, en México se ha denominado fuero ${ }^{74}$ constitucional a lo que en el constitucionalismo se conoce como inmunidad parlamentaria, designando de esta forma como procedimiento para la declaración de procedencia al procedimiento de resolución de suplicatorio. Es el artículo 61 Constitucional el que consagra la figura jurídica del Fuero, mientras que el correspondiente artículo 111 el que establece la figura de la declaración de procedencia.

A decir del citado artículo 61 el fuero constitucional se establece como una atribución del Presidente de la Cámara en cuanto a su efectiva garantía, pues establece la obligación de éste de velar en todo momento por el respeto al fuero de los miembros, así como el de garantizar la inviolabilidad del recinto en que se sesiona, ello con la finalidad de lograr la absoluta independencia del ejercicio legislativo.

El fuero constitucional se ciñe irremediablemente al calce de la declaración de procedencia que establece como requisito de procedibilidad el artículo 111 Constitucional, que por mando jerárquico se lleva a cabo en la Cámara de Diputados, ya se trate de Diputados o Senadores, siendo la cámara baja la que centra la facultad de decisión sobre si se ha de proceder o no contra del parlamentario. Tal garantía de fuero sólo hace las veces de salvaguarda para los casos de orden penal, no así para los de materia civil, para los cuales no se requiere declaración de procedencia.

Caso contrario a lo que opera para el caso español, respecto a la denegación del suplicatorio, en el caso mexicano la negación de la declaración de procedencia no prejuzga sobre los fundamentos de la imputación, por lo que, en consecuencia, una vez fenecido el término del encargo del parlamentario se puede dar continuidad a la investigación dejando

\footnotetext{
${ }^{73}$ Pacto Internacional de Derechos Civiles y Políticos

74 Para la doctrina mexicana, el fuero constitucional implica un "conjunto de normas aplicables a determinados servidores públicos que en razón de la función que desempeñan quedan sujetos a un régimen propio en cuanto a la exigencia de ciertas responsabilidades en las que puedan incurrir por su conducta". ANDRADE SÁNCHEZ, Eduardo, El desafuero en el sistema constitucional mexicano, UNAM, México, 2004, p. 4.
} 
a salvo los derechos de la fiscalía para poder volver a solicitar el inicio del proceso judicial contra del ahora ya ex funcionario.

Por el contrario, si la declaración de procedencia es afirmativa la protección procesal cesará quedando el parlamentario separado de su cargo en tanto esté sujeto al proceso penal. En el caso de que dicho proceso terminase con una sentencia absolutoria, el inculpado podrá reasumir su función como diputado o senador. A este proceso que encabeza la declaración de procedencia se denomina procedimiento de desafuero y se constituye como el mecanismo constitucional para separar al parlamentario de sus funciones y ponerlo a disposiciones de las autoridades penales. Lo anterior en relación con los artículos 108, párrafo primero, 109, fracción II y párrafo último, así como el artículo 111, párrafos primero al tercero, sexto y séptimo, constitucionales.

Al igual que en el caso español, la garantía de fuero constitucional en México es aplicable tanto a parlamentarios, como a otros miembros que conforman los poderes de la unión. Esta inmunidad está contemplada en el artículo 61 y 111 constitucionales, aplicables tanto a los Secretarios de Estado y a otros funcionarios públicos, así como a ciertos miembros del Poder Judicial, es decir, esta figura jurídica es propia de los tres poderes. Por esta razón podríamos afirmar que se trata de mantener el equilibrio al seno del Estado, a pesar de ser un sistema en donde predomina el Poder Ejecutivo.

Otra de las características que diferencia el fuero constitucional mexicano de la figura del aforamiento español, es el hecho que para el primero si bien la palabra per se implica una connotación de jurisdicción, no es motivo para que se geste una jurisdicción específica para las personas aforadas, puesto que en México una vez llevado el juicio de procedencia contra un diputado o senador y que el mismo sea concedido, la jurisdicción ordinaria del delito de que se trate será la encargada de enjuiciar al legislador, existiendo para el caso el mismo trato jurídico que cualquier ciudadano.

Estructura constitucional que se concatena con lo establecido por el artículo 13 Constitucional que prohíbe la creación de fueros distintos a los ordinarios, con la salvedad del fuero militar, por tanto, aun cuando se trate de un representante federal el fuero que ha permanecer es el ordinario y no uno especial, tal es el caso del sistema español.

Por último, cabe señalar que a diferencia de España para quien la resolución del suplicatorio (denegación) puede ser impugnada vía juicio de amparo, en México es el propio ordenamiento constitucional en su artículo 111 el que establece la inatacabilidad de la denegación de la declaración de procedencia, pues para el efecto el fuero simplemente suspende el cauce penal, hasta en tanto el parlamentario tenga tal investidura.

\section{CONCLUSIONES}

En concreto se realiza un análisis comparativo de las figuras jurídicas de protección parlamentaria dentro de los ordenamientos constitucionales de España y México, en tanto a su naturaleza, utilidad y efectos dentro de su estructuración procesal al igual que en su 
utilización jurídico-política. Dejando constancia del uso de estas figuras jurídicas como pilares fundamentales del Estado Democrático de Derecho.

Aunque suelen considerarse frutos del pensamiento medieval inglés, el uso y configuración de la inviolabilidad e inmunidad evidentemente no sirve a los mismos fines con que fueron creadas. Las mismas deben ser consideradas como garantías de la organización política actual, ya no como privilegios dentro de un sistema absolutista. Son evidencias de una evolución democrática que incluye sectores populares diversos.

Respecto a la inviolabilidad debe destacarse que la percepción de ambos ordenamientos constitucionales (España y México) resulta homologable ya que en ambos campos jurídicos implica connotación de protección, constituida como una plena irresponsabilidad penal por razón de la libertad de expresión de la que todo parlamentario goza. Y no es que con ello se corrompa como se ha dicho el esquema constitucional, pues no hay que dejar de lado que más allá de un enfoque jurídico existe el de corte sociológico-político, que implica que una apreciación reduccionista de tal prerrogativa traería consigo consecuencias agravadas para el Estado Democrático Constitucional respecto a la representatividad de la soberanía nacional.

La inmunidad como institución procesal actúa precisamente como un medio o condición de procedibilidad y no como una irresponsabilidad. Para ambos casos en comparación, resulta la misma suerte de percepción. Para el caso mexicano la praxis interpretativa in extenso realizada por el tribunal supremo realiza suerte de mutación constitucional, transformándola fuera de los mecanismos formales de reforma, pretendiendo dar una continuidad y estabilidad al derecho, no representando un cambio formal al texto constitucional sino material a través de la jurisprudencia.

El uso de la inmunidad parlamentaria en ningún momento corrompe el principio de igualdad al ser una norma amparada por el designio constitucional, misma que encuentra su justificación en la esencia de la supremacía constitucional, que se instaura en miras organizativas del Estado Democrático de Derecho, sirviendo como un engranaje más de la maquinaria estatal. Por tanto, la justificación radica precisamente en el telos de tal prerrogativa, por lo que no se le tendría que tildar de oposición a derechos fundamentales, pues las necesidades sociales en tanto a la organización del poder ponderan el ejercicio del actor político.

Por su cuenta esta resulta ser sin duda la mayor diferencia dentro del estudio comparativo. La aplicabilidad y percepción que de la inmunidad se tiene en el Estado mexicano es referida a la totalidad de las prerrogativas analizadas, situando a la inviolabilidad y al fuero constitucional como inmunidades.

La segunda postura de interés comparativo resulta ser el efecto práctico que para los casos establece el uso de la condición de procedibilidad que se da vía suplicatorio y vía declaración de procedencia respectivamente, puesto que, en el primer caso la denegación implica una suerte de inmunidad plena en cuanto hace a la consideración de sobreseimiento libre, más para la segunda en cita sólo implica una dilación procesal de orden suspensivo. 
Es apreciable la configuración que denota la jurisdicción operante en el sistema español ya que implica la generación de un juicio uniinstancial ante la Segunda Sala del Tribunal Supremo, en los casos concretos de procedimiento de desaforamiento. Para México la concesión de la declaración de procedencia implica un juicio de desafuero mediante el cual se desconocen todas y cada una de las garantías que envisten al parlamentario, supeditando su proceso penal al conocimiento del juez ordinario desconociendo la doctrina del "juez natural" que consagra el esquema español, ocasionando con ello una revitalización desde el ordenamiento común del principio de igualdad ante la ley y el principio de debido proceso respecto al recurso eficaz, situando el proceso contra el exparlamentario en el uso de poder impugnar la resolución en segunda instancia e incluso poder optar por una tercera instancia que sería el juicio de amparo.

Percepción que puede resultar contrapuesta acorde a la fundamentación que España hace para la consagración de la independencia y autonomía del Poder Judicial, en el entendido de que por vía de la opinión pública se pueda ver mermado la apreciación del juez común por la intimidación que el poder parlamentario pudiese llegar a ocasionar.

Las figuras jurídicas de protección parlamentaria dentro de los ordenamientos constitucionales de España y México resultan similares terminológicamente, pero disimiles en su esencia y estructuración procesal, al igual que en su rol jurídico-político. Si bien, ambos países comparten una tradición jurídica, resulta evidente que la practicidad resulta no homologable, pues las instituciones jurídicas se encaminan en diferentes posturas. Sin embargo, ambas comparten la finalidad última de la instauración de tales prerrogativas, a saber, el soporte constitucional del Estado Democrático de Derecho, mediante la valía del principio de división de poderes y de representatividad de la nación soberana.

En caso de que la inviolabilidad y la inmunidad menguaran o desaparecieran, implicaría que el parlamentario quedase expuesto sin más a cualquier tipo de ataque político instrumentado incluso en alcance del ius puniendi. Pues precisamente éstas garantías marcan un claro límite al derecho punitivo del que gozan los otros poderes constituidos, siendo necesario para la vida democrática tal protección sin mayor limitación que la signada por el constituyente.

En otras palabras, el peligro no radica en la afectación a las garantías parlamentarias de inviolabilidad y/o inmunidad in aula, se trata por el contrario de comprender que tales garantías no se instauran en términos singulares, sino en posturas colectivas, no instituidas para el representante en lo singular, sino para el órgano representativo del cuerpo electoral. Recuérdese que el representante es un actor político con facultades de vital importancia para la organización política, investido con poderes de decisión respecto a su potestad legislativa y por tanto como agente conformador de la voluntad popular en opinión pública y precisamente por tal condición de actor político es inevitable que el mismo deba en su momento priorizar los intereses sociales que se demandan, resultando necesario esta actividad en el ámbito de la legislatura ocasionando ambientes hostiles y por consiguiente de reacción política. 
Garantías estructurales que se establecen como mecanismos constitucionales de control del poder político. El solo hecho de sugerir su desaparición o minimización supone un juego de inconstitucionalidad en la organización estatal. En todo caso, sólo es legítimo el limitar el alcance en la observación de las mismas. Al ser instituciones de orden constitucional, resultan ser preceptos que forman parte de la norma suprema y, por tanto, comparten esa misma supremacía.

Por tanto, la inmunidad, la inviolabilidad y el aforamiento resultan ser instituciones nacidas en consecuencia inmediata de ponderación de la división de poderes para dar autonomía e independencia al parlamento, respecto de los demás poderes de la nación. A la vez esta división de poderes concreta la democracia constitucional entendiendo para ello que sin control democrático no existe Estado de Derecho, por tanto, al ser estas instituciones una garantía necesaria no sólo del parlamento sino de todo el cuerpo electoral en sentido estricto, resultan ser un presupuesto necesario para el propio Estado Democrático de Derecho y por consiguiente no sólo un elemento esencial del orden jurídico, sino un cimiento obligado de éste en la estructuración nacional que bien pudiese señalarse incluso como un ius cogens de la democratización estatal, enalteciendo con ello al mismo régimen democrático, concluyendo -como irrestrictamente lo ha defendido Ruipérez citando a Pedro de Vega- que, el "único régimen éticamente defendible, políticamente coherente y científicamente explicable es el régimen democrático.

\section{BIBLIOGRAFÍA}

ABELLÁN-GARCÍA GONZÁLEZ, El estatuto de los parlamentarios y los derechos fundamentales, Madrid, 1992.

ALFONSO DE ANTONIO, Ángel Luís, "El suplicatorio como manifestación de la inmunidad parlamentaria”, en RFDUC, nº 86, curso 1994-1995, Madrid, 1996.

ANDRADE SÁNCHEZ, Eduardo, El desafuero en el sistema constitucional mexicano, UNAM, México, 2004.

BARTHÉLEMY, Joseph y DUEZ, Paul, Traité de Droit Constitutionnel, Dalloz, Francia, 1933.

BLASCKSTONE, Comentarios, Libro I, Capítulo II, Sección 3a: "This Bering the place where that absolute despotic power wich must all goverments reside somewhere, is entrusted by Constitution of this Kingdom"

BOCKELMANN, Die Unverfolgbarkeit der Abgeordneten nachdeutschen Immunitätssrecht, Gotinga, 1951. 
BRADLEY, A. W. Y EWING, K. D., Constitutional and Administrative Law, 13. ad., Essex (England), Pearson-Longman, 2003.

BUGALLAL, Gabino, Inviolabilidad Parlamentaria, Real Academia de Ciencias Morales y Políticas, Madrid, 1921.

CARRIÓ, G. R., en "Nota Preliminar" a la obra de W. N. HOHFELD, Conceptos jurídicos fundamentales, por GARZÓN VALDÉS, Ernesto y VÁZQUEZ, Rodolfo (Dirs.), $3^{\mathrm{a}}$ ed., México, 1995.

CARRÉ DE MALBERG, Raymond, Contribución a la Teoría General del Estado, Edit. Dalloz.

CARRO MARTÍNEZ, Antonio, "La Inmunidad Parlamentaria”, en RDPol, nº 9, 1981.

CÁTALA I BAS, Alexandre, "La Inviolabilidad a la luz de la sentencia del TSJ del País Vasco de 5 de septiembre de 2003, (Caso del Diputado de H.B. Jon Salaberria), en CortsADP, $\mathrm{n}^{\circ} 14,2003$.

CID VILLAGRASA, Blanca (Dir.), y RECODER VALLINA, Tatiana, El Parlamento ante los Tribunales, Edit. Aranzadi, España, 2015.

VALDÉS SÁNCHEZ, Clemente, La Constitución como instrumento de dominio, Editorial Coyoacán, México, 1996.

CONDE DE TEJADA DE VALDOSERA, De la índole y extensión de las inmunidades parlamentarias, Madrid, 1894.

DE LA CUEVA, Lucas Murillo, "Garantías de los miembros del Parlamento Vasco", en REP, no 46-47, 1985.

DE VEGA GARCÍA, Pedro, "El Principio de publicidad parlamentaria y su proyección constitucional", en REP, No 43, enero-febrero 1985, España, pp. 45-65.

DE VEGA GARCÍA, Pedro, Estudios Político Constitucionales, IIJ UNAM, México, 1987;

DE VEGA GARCÍA, Pedro, La Reforma Constitucional y la Problemática de Poder Constituyente, Edit. Tecnos, España.

ESMEIN, Adhémar, Éléments de Droit constitutionnel français et comparé, $6^{\mathrm{a}}$ ed., Sirey, París, 1914.

ESMEIN, Adhémar y NÉZARD, Henry, Éléments de Droit Constitutionnel Français et Comparé, vol. II. 
FERNÁDEZ-MIRANDA y CAMPOAMOR, Alfonso, "Artículo 71. Inmunidad e Inviolabilidad Parlamentarias", en Comentarios a las Leyes Políticas, Dirigidos por Oscar Alzaga, Edit. Edersa, España, 1989.

FERNÁDEZ-MIRANDA y CAMPOAMOR, Alfonso, "La Inmunidad Parlamentaria en la práctica de la II República y de las Cortes Constituyentes", en REOP, nº 47, 1977.

FERNÁDEZ-MIRANDA y CAMPOAMOR, Alfonso, "Origen histórico de la inviolabilidad e inmunidad parlamentaria", en Revista de la Facultad de Derecho, Universidad Complutense, $\mathrm{N}^{\mathrm{o}}$ monográfico 10, 1986.

FERNÁDEZ-MIRANDA y CAMPOAMOR, Alfonso, "La Inmunidad Parlamentaria en la actualidad", en Revista de estudios políticos, n 215, 1977.

FERNÁDEZ-MIRANDA y CAMPOAMOR, Alfonso, "Artículo 71. Inviolabilidad e inmunidad parlamentarias", en Comentario a las Leyes Políticas, O. Alzagar (dir.), Vol. VI, Madrid, 1989.

FERNÁDEZ-MIRANDA y CAMPOAMOR, Alfonso, "La inmunidad parlamentaria en la práctica de la II República y de las Cortes orgánicas", en Revista Española de la Opinión Pública, nº. 49, 1977.

FERNÁNDEZ-VIAGA BARTOLOMÉ, Plácido, El Juez natural de los Parlamentarios, Civitas, Madrid, 2000.

FIGUERUELO BURRIEZA, Ángela, "Derechos fundamentales y abuso de inmunidad", en Memorias del IV Congreso Iberoamericano de Derecho Constitucional, México, IIJUNAM, 1992.

FIGUERUELO BURRIEZA, Ángela, “Opinión pública, principio de publicidad y garantías parlamentarias”, en $R C G, \mathrm{n}^{\circ} 14,1988$.

FRAGA IRIBARNE, Manuel, "Los Privilegios de los Procuradores y el nuevo Reglamento de las Cortes Españolas", en REP, $\mathrm{n}^{\circ}$ 99, mayo-junio 1985, pp.57-82.

FRAGA IRIBARNE, Manuel, El Reglamento de las Cortes españolas, Madrid, 1959.

GARCÍA, Eloy, Inmunidad Parlamentaria y Estado de Partidos, Edit. Tecnos, España, 1989.

GRAMSCI, Antonio, Cuadernos de la Cárcel. Notas sobre Maquiavelo, sobre política y sobre el Estado Moderno, Juan Pablos Editor, México, 2009.

HABERMAS, Jürgen, Historia y Crítica de la opinión pública, Barcelona, 1981.

HELLER, Hermann, Teoría del Estado. Teoría política, ed. 39, Edit. Porrúa, México, 2005. 
I. LOVELAND, Constitutional Law, Administrative Law and Human Rights (A Critical

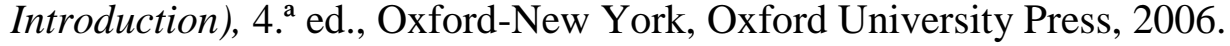

JELLINEK, Georg, System der subjektiven öffentlichen Rechte, pp. 161-162. Así en: C. BRUNO, De la Garantie politique des membres du Reichstag pour faits accomplis hors de leurs fonctions, Thèse, París, 1905.

KELSEN, Hans, Teoría General del Estado, 5ta ed., Edit. Coyoacán, México, 2015.

MARTÍN DE LLANO, María Isabel, Aspectos constitucionales y procesales de la inmunidad parlamentaria en el ordenamiento español, Dykson, España, 2010.

MARTÍNEZ SOSPEDRA, Manuel, Privilegio Discutido: La Inmunidad Parlamentaria en Derecho Español, Cuadernos del Senado, España, 2004.

MARTÍN-RETORTILLO BAQUER, Lorenzo, "El amplio margen de libertad en el uso de los privilegios parlamentarios y su incidencia sobre los derechos fundamentales", en $R E D C, \mathrm{n}^{\circ} 11,1984$.

MATTEUCCI, N., "Le radice striche della Costituzione e i nuovi problema di libertà", en Aa Vv., La Costituzione Italiana: i principi, la realtà, Milán, 1977.

MOHRHOFF, F., “Camera dei Diputati”, en Novísimo Digesto italiano, II, $3^{\mathrm{a}}$ ed., Torino, Az-Cas., 1957.

MONTESQUIEU, De L'Esprit des Lois, Libro XI, Cap. V.

PORTERO, Inviolabilidad e inmunidad parlamentarias, Málaga, 1979; GÓMEZ BENÍTEZ, "La inviolabilidad e inmunidad parlamentarias", en Rev. F. Derecho, n' 64, 1982.

PUNSET BLANCO, R., Las Cortes Generales, Madrid, 1983, p153; y Estudios Parlamentarios, Madrid, 2001.

RECODER DEL CASO, Emilio, "Comentario al Artículo 71 de la Constitución", en Comentarios a la Constitución dirigidos por Garrillo Falla, Madrid, 1987.

RUBIO LLORENTE, Francisco, "Parlamento y representación política", en Primeras Jornadas de Derecho Parlamentario, Madrid, 1985.

RUIPÉREZ ALAMILLO, Javier, Libertad Civil e Ideología Democrática. De la conciliación entre democracia y libertad a la confrontación Liberalismo-Democracia, IIJ UNAM, México, 2008 
RUIPÉREZ ALAMILLO, Javier, Reforma vs. Revolución. Consideraciones desde la Teoría del Estado y de la Constitución sobre los límites materiales a la revisión constitucional, Edit. Porrúa, México, 2013.

SAAVEDRA GALLO, Pablo, "Privilegios personales de carácter jurisdiccional y procesal en materia penal", en $R U D P, \mathrm{n}^{\circ} 0,1988$.

SANTSCHY, Le Droit Parlementaire en Suisse et en Allemagne, Neuchâtel, 1982.

SCHMITT, Carl, Teoría de la Constitución, Madrid, 1934.

SCHMITT, Carl, La defensa de la Constitución, Madrid, 1983.

SIEYÉS, E., "Essai sur les privilèges", en Écrits politiques, Choix et présentation de ZAPPERI, Roberto, EAC, París, 1985.

SURLESE, Laura, Il Re e i Lords nel Parlamento medievale inglese, cit. Cap. VIII.

TRAVERSA, J., "Immunità parlamentare”, en Enciclopedia del Diritto, vol. XX (IngInch), Milán, 1970.

VIANA BALLESTER, Clara, Inmunidades e inviolabilidades: naturaleza jurídica y concepción dogmática. Especial referencia a la inviolabilidad parlamentaria, Congreso de los Diputados, serie monografías, número 84, España, 2011.

WONG MERAZ, Víctor Alejandro, Constitución Mexicana. Reforma y Mutación, Edit. Porrúa, México, 2010

WONG MERAZ, Víctor Alejandro y CABANAS VEIGA, Manuel, "Los Derechos Sociales como límite de la Reforma Constitucional, un análisis desde su concepto y la teoría de la Constitución", en Derechos Humanos. Realidades y Desafios, Edit. vLex, México, 2016.

ZAGREBELSKY, Gustavo, Le immunità parlamentari. Natura e limiti di una garanzia costituzionali, Turín, 1979.

ZANGARA, A., "Prerrogativi Costituzionali (Notazioni e spunti)", en Scritti in onore di G. Ambrosini, III, Milán, 1970. 